\title{
Endocrine Secretory Inhibition
}

National Cancer Institute

\section{Source}

National Cancer Institute. Endocrine Secretory Inhibition. NCI Thesaurus. Code C41494.

Endocrine Secretory Inhibition involves interference with, or restraint of, hormone release into the bloodstream from endocrine glands. Alteration of positive or negative feedback mechanisms can inhibit hormone release. 